\title{
Reopening of School in COVID I9 Pandemic
}

\author{
Jugal Kishore
}

Director Professor \& Head, Department of Community Medicine, VMMC \& Safdarjung Hospital (Ministry of Health \& Family Welfare), New Delhi, India.

DOI: https://doi.org/10.24321/2349.2880.202004

\section{I $\quad \mathbf{N} \quad \mathbf{F} \quad \mathbf{O}$}

E-mail Id:

drjugalkishore@gmail.com

Orcid Id:

https://orcid.org/0000-0001-6246-5880

How to cite this article:

Kishore J. Reopening of School in COVID 19

Pandemic. Ind J Youth Adol Health 2020; 7(1):

23-26.

Date of Submission: 2020-08-01

Date of Acceptance: 2020-08-23

\section{Risks and Benefits of Opening of Schools}

Corona Virus Disease 2019 (COVID-19) is a newly identified disease caused by the virus Subacute Respiratory Syndrome Corona Virus 2 (SARS-CoV-2). We are still learning about how it spreads, how it affects children, and what role children may play in its spread or control. From the available literature, it is quite clear that children are less likely to get COVID-19 than adults, and when they do get disease, they generally have less serious illness than adults. Common symptoms of COVID-19 among children include fever, cough, runny nose, sore throat, headache, body ache, and diarrhoea; many children may have mild or no symptoms. Most children becoming infected by a family member. From the disease dynamics, it is also known that the more individuals a child interacts with, and the longer the interaction, the higher the risk of COVID-19 spread. The risk of getting COVID19 is also influenced by the intensity of transmission and higher prevalence of disease in the community. Therefore, reopening of school may be considered keeping these risk factors in mind.

As schools reopen, more will be learned about the feasibility and effectiveness of mitigation strategies such as wearing cloth face coverings and keeping people 6 feet apart through social distancing. Regardless of the level of community transmission, vigilance to practicing behaviours that prevent spread among everyone at school and taking other recommended actions to plan, prepare, and respond to COVID-19 will lower the risk of SARS-CoV-2 transmission than it might otherwise would be necessary for all other communicable diseases.

Some children may be at increased risk of getting COVID-19 or may be at increased risk for severe illness from COVID-19. For these children, parents and caregivers may need to take additional precautions with regard to school re-entry. There are more COVID-19 cases reported among children with intellectual and developmental disabilities than those without. Children may be at a higher risk of getting infection if they are already having any comorbidity such as respiratory diseases such as asthma, bronchitis, who have neurologic, genetic, metabolic conditions, or who have congenital heart disease, or in an immunocompromised state.

There are few reports describing that certain group of children and adolescents are admitted to intensive care units with multisystem 
inflammatory conditions. But these are case reports and case series only describing acute illness presenting hyperinflammatory syndrome leading to multiorgan failures. Further observations are required to rule out any other cause of such severe consequences.

We should also keep in mind that during lockdown and closure of schools, there are increase incidences of Sexual Child Abuse, child labour, domestic violence which has lifelong impact on children.

Schools provide important services and supports for children's academic, social-emotional and physical health. For instance, social interaction among children in grades $\mathrm{K}-12$ (from kindergarten to 12 th grade) is important not only for emotional wellbeing, but also for children's language, communication, social, and interpersonal skills. Some students may have experienced social isolation and increased anxiety while not physically being in school due to COVID-19. Schools also provide critical services, such as mid-day meal programs, skill training, and behavioral and mental health services. Continuity of other special services is important for student success and lack of access to these services and supports have the potential to widen existing disparities and cause long-term effects on children's educational outcomes, health, and the economic wellbeing of families and communities.

\section{Precautions to Safeguard the School Shildren}

Schools are part of social capital of the society which provide safe, supportive learning environment to the students and provide jobs to teachers and supporting staff and also allow parents and guardians to carry out their professions.

Communities should make every effort to support the reopening of schools safely for in person learning in next few weeks and months. From other countries, we know that schools can reopen safely for in-person learning in communities with low rates of COVID-19 spread if appropriate precautions are taken. Each state of the country like India can create local task force which is comprising of representatives from politics, schools, families, and social welfare departments who can identify mitigation strategies, to decrease community transmission of the virus without affecting their interests and children's welfare. In such groups representation of professional body could be useful for highlighting the scientific evidence of certain preventive strategy.

Schools can implement strategies across 4 key areas to reduce the spread of COVID-19:

- $\quad$ Promoting healthy behaviours that reduce spread (e.g. social distancing, washing hands and wearing cloth face coverings)

- Maintaining healthy environments (e.g., ensuring proper ventilation, cleaning and disinfecting frequently touched surfaces)

- Maintaining healthy operations (e.g., staggering schedules, keeping students in small groups, Cohorting, Alternative schedule, Hybrid model, blended learning) - $\quad$ Preparedness for any eventuality or development of sign and symptoms.

\section{Promoting Healthy Behaviours that Reduce Spread of Infection}

School administration can take everyday preventive actions to protect themselves and others from getting infection. Washing hands often with soap and water for at least 20 seconds is easiest practice which can be adopted by all. If soap and water are not readily available, use a hand sanitizer that contains more than $60 \%$ alcohol is a good alternative. Covering all surfaces of hands and rubbing them together until they feel dry. Covering coughs and sneezes with a tissue or inside of elbow, throwing the tissue away, and then washing hands. Avoiding touching one's eyes, nose, mouth, and face cover or mask. Maintaining distance of at least 6 feet from other adults, and from students when feasible. Wearing a face mask covering nose and mouth especially when other social distancing measures are difficult to maintain.

\section{Maintaining Healthy Environment}

Cleaning and disinfecting frequently touched surfaces, including tables, doorknobs, light switches, countertops, handles, desks, phones, keyboards, toilet sheet or tap, faucets, and sinks. Staying home when sick, or after being in close contact with a person with COVID-19. Initially such places and objects can be avoided where transmission through fomites is higher such as gyms, physical education equipment, games equipment, etc.

School buses and other transport medium of students are common source of virus transmission. Therefore, drivers, and carer should practice all safety measures and adhere to all protocols (e.g., hand hygiene, face mask, keeping cleanliness of buses, seats, etc). Similar to frequently touched surfaces, buses should be cleaned and disinfected at least daily using disinfectants. Students should be seated with distance in buses and always use face mask and avoid overcrowding in the bus. However, students who live in the same household may sit together if needed. If students are wearing face mask then sitting two in a row may not be a problem of transmission.

Schools may consider alternative strategies to accommodate the reduced number of students in buses, such as staggered pick up and drop off times or additional bus routes. Schools should consider having spare, clean face masks available to ensure all students wear face mask coverings on the school bus. Drivers can open bus windows to increase circulation of outdoor air, but should ensure that doing so does not 
pose a safety or health risk (e.g., risk of falling).

Schools can educate staff and families about when they or their children should stay home and when they can return to school, while actively encouraging employees and students who are sick or who have recently had close contact with a person with COVID-19 to stay home.

Schools can teach and reinforce handwashing practices among all students, teachers, and staff. Schools can also use physical guides, such as tape on floors or sidewalks, one-way routes in hallways, and signs on walls to help students, teachers, and staff remain at least 6 feet apart. Schools can implement flexible sick leave policies and practices that enable staff to stay home when they are sick, have been exposed, or are caring for someone who is sick.

It is well known that the closer, longer, and more frequent the interaction between students, teachers and staff, the higher the risk of respiratory droplets being passed between them. Therefore, it is recommended to keep a distance of at least 6 feet from each other, in addition to practicing face mask, washing hands often with soap and water, and staying home when sick.

Improving ventilation systems in the classrooms and halls is beneficial to reduce transmission of Covid-19. If this is difficult schools can also consider using outdoor space for open classes. Waste disposal and cleanliness should be done regularly in the school.

Many countries have staggered attendance and their start and dismissal times, or they have created alternating shifts of students to enable social distancing. In higher classes online classes may be suitable, avoiding smaller children to get online or increasing their screen time. Senior students may be called to school only for practical exercises.

For example: Denmark was the first European country to reopen schools. Denmark staggered students' re-entry dates (e.g., one group started school first, followed by another group at a later date). Denmark limited class sizes and used other social distancing measures. Younger students (under age 12) returned first based on their likely lower health risk, need for more supervision, and lower benefit from virtual learning compared to older students. Class sizes were reduced to allow physical distancing. Denmark has seen decreased infections among all age groups since schools reopened. In comparison to Denmark, Germany reopened for older students with students attending in alternating shifts to ensure a maximum class size of 10 .

Maintaining Healthy Operations (e.g., Staggering Schedules, Keeping Students in Small Groups, Cohorting, Alternative Schedule, Hybrid Model, Blended Learning)

One important strategy that administrators can consider is cohorting, which forms groups of students, and sometimes teachers or staff, that stay together throughout the school day to minimize exposure for students, teachers, and staff across the school environment. Ideally, students and staff within a cohort would only have physical proximity with others in the same cohort. This practice may help prevent the spread of COVID-19 virus across students, teachers, and staff of different classes. This will also facilitate more efficient contact tracing if anyone found positive case in the cohort, and allowing for targeted testing, quarantine, and isolation of a single cohort instead of whole school. Many innovations may be tried to accommodate all students without increasing risk.

An alternating schedule can be practiced where students rotate when they physically attend school. This is also sometimes called a hybrid schedule (mix of in-person and virtual school). For example, certain grades or classrooms may attend school on Monday or Tuesday or Thursday or Friday alternatively. The school would be thoroughly cleaned on Wednesday. As another example, some schools have rotated in-person attendance weekly with one group of students attending during a week, followed by a different group the next week in rotation.

Before reopening of schools well define plan and strategy to implement it should be in place and risk of infection to the community and children should be assessed without compromising students' educational and emotional needs. These strategies are limiting class sizes, cohorting, or alternative hybrid scheduling, use of face mask, proper hygiene, school cleaning, etc.

\section{Preparedness for any Eventuality or Development of Sign and Symptoms}

Each staff can be trained to identify signs and symptoms of Covid-19 so that they can stay home or consult doctors. Similarly, COVID-19 information booklet may be circulated to all parents to protect their children and themselves from any risk exposure and measures taken in case of sickness.

This can be concluded that there is lack of evidence of transmission of Covid 19 to the community or school staff by the students. In view of lack of equitable access to online classes to all school students, millions of them lagging behind in learning. With the unknown burden of losses to the future generation it would be highly recommended that schools are opened with proper planning and strategy as soon as possible.

\section{Conflicts of Interest: None}

\section{References}

1. https://www.unicef.org/coronavirus/what-will-returnschool-during-covid-19-pandemic-look.

2. https://www.who.int/news-room/detail/10-03-2020- 
covid-19-ifrc-unicef-and-who-issue-guidance-toprotect-children-and-support-safe-school-operations.

3. https://www.cdc.gov/coronavirus/2019-ncov/dailylife-coping/children.html.

4. Viner RM, Russell SJ, Croker H, Packer J, Ward J, Stansfield C, Mytton O at el. School closure and management practices during coronavirus outbreaks including COVID-19: a rapid systematic review. Lancet Child Adolesc Health 2020; 4: 397-404.

5. https://www.ucl.ac.uk/news/2020/may/childrenappear-half-likely-catch-covid-19-adults. 